\title{
RULMANLI YATAKLARDA ETKİLI OLAN HERTZ BASINÇLARININ VE YUVARLANMA ELEMANLARINDA OLUŞAN DEFORMASYONLARIN ANALIZI
}

\author{
$\operatorname{Emin} G \ddot{U} L L \ddot{U}^{*}$ \\ Tufan Gürkan YILMAZ*
}

Alınma: 14.11.2016; düzeltme: 01.12.2017; kabul: 01.03.2018

Öz: Bu çalışmada elastisite teorisinden bilinen, yarı sonsuz cisimler için geliştirilmiş ve yayılı bir yükün ya da bir kuvvetin sebep olduğu deformasyonları veren ifadeler kullanılarak; bilyeli ve makaralı rulmanlı yataklar için Hertz basınç dağılımları ve bu basınçların sebep olduğu deformasyonlar hesaplanmıştır. Bunun için önce bilye ve makaralı rulmanların, çeşitli yükler altındaki elips ya da dikdörtgen şekilli Hertz basınç alanları hesaplanmıştır. Sonrasında ise elips veya dikdörtgen alanlar sonlu fark alanlara bölünerek, sonsuz küçük basınç alanları bulunmuş ve burada etkili olan basınçlar kullanılarak, alanlar üzerinde etkili olan kuvvetlere dönüştürülmüştür. Çözümde, bir kuvvet ele alınmış, bunun yeterli mesafelerdeki sebep olduğu deformasyonlar bulunmuş, sonra her nokta için diğer kuvvetlerin sebep oldukları deformasyonlarda bulunmuş ve bunların her biri üst üste toplanarak, bir nokta için toplam deformasyonlar bulunmuş̧ur. Neticede her bir nokta için basınç denklemi ile deformasyon denklemi geliştirilen program sayesinde çözülmüştür. Programın esnekliği sayesinde yük, malzeme, bilye ve makaranın boyutları ve eğrilik yarıçapları değiştirilmek suretiyle, bunların basınç ve deformasyonlar üzerine etkileri incelenmiştir.

Anahtar Kelimeler: Sabit bilyeli yatak, Silindirik makaralı yatak, Hertz basınçları, Deformasyon

\section{Analysis of Hertz Pressure Effect on Bearings and Deformation on Rolling Elements}

\begin{abstract}
In this study, Hertz pressure distributions and deformations are calculated for ball and roller element bearings by using equations of deformations, developed for semi-infinite bodies, which is resulted from forces, it is also known from theory of elasticity. Firstly, area of Hertz pressure which has elliptical or rectangular shape are calculated for various load in ball element and roller element bearings. Then elliptical or rectangular areas are divided into small areas. Finally forces on each point of area are obtained. Calculated forces cause deformation for adequate distance from action point. All deformations are summed for each point. On conclusion, pressure and deformation equations are solved for each point of area. Effects of load, material, dimensions of ball and race conformity on hertz pressure and deformation are investigated by developed program.
\end{abstract}

Keywords: Ball element bearings, Roller element bearings, Hertz pressure, Deformation

\section{GIRIŞ}

Rulmanlarda olduğu gibi temasta bulunan iki yüzey arasında meydana gelen gerilmelere yüzey gerilmeleri denir. Aslında basınç şeklinde olan bu gerilmeler ile basma gerilmeleri arasında şu fark vardır. Basma gerilmeleri kuvvetin etkisi altında bir elemanın kesitinde

\footnotetext{
* Uludağ Üniversitesi Mühendislik Fakültesi, Makine Mühendisliği Bölümü, Görükle, 16059 Bursa.

İletişim Yazarı: Tufan Gürkan YILMAZ (tufanyilmaz@uludag.edu.tr)
} 
meydana gelen gerilmelerdir ve mukavemet esaslarına göre kuvvet-gerilme denge denklemlerinden elde edilir. Yüzey gerilmeleri ise, kuvvetin etkisi altında temas yüzeylerinde meydana gelen gerilmelerdir ve aslında temas yüzeylerinin büyüklüğüne bağlı olmak üzere iki şekildedir. Temas yüzeylerinin ve elemanlarının boyutları aynı mertebede olduğu takdirde yüzey basıncı, temas yüzeylerinin boyutları elemanların diğer boyutlarına oranla pek küçük değerde bulunmaları halinde Hertz Basıncı söz konusudur. Bu yüzey basınçları arasındaki fark yalnız tanımlama bakımından değil, yüzey basınçlarının tayininden de ileri gelir. Yüzey basınçları basma gerilmelerine benzer bir bağıntı ile hesaplanırken, Hertz Basınçları, Elastisite Teorisi'nin esaslarına göre tayin edilir. İki eleman arasındaki teorik temas nokta veya çizgi olduğu takdirde, dış kuvvetlerin etkisi altında meydana gelen deformasyon sonucunda, teorik nokta daire veya elips, teorik çizgi ise dikdörtgen şeklini alır. Teknikte bu çeşit deformasyonlara rulmanlarda, dişli çarklarda, sürtünme çarklarında ve kam mekanizmalarında rastlanır. Yüzeydeki basınç ve deformasyonlar Hertz Teorisi'ne göre hesaplanır. Bu teori şu kabulleri yapmaktadır: Temas yüzeylerinin boyutları elemanların diğer boyutlarına göre çok küçüktür.

Deformasyonlar, elastik deformasyon şeklindedir. Hooke Kanunu geçerlidir. Temas yüzeylerinde kayma yoktur. Birbiri üzerinde yuvarlanan ve normal doğrultuda bir kuvvetle birbirine bastırılan iki elastik yuvarlanma elemanın yüzeylerinde bir yassılma durumu ortaya çıkar. Deformasyon nedeniyle farklı eğrilik yarıçaplarının sonucu olarak kaymasız bir yuvarlanma hareketinde dahi, hiçbir relatif hareketin mevcut olmadığı temas yüzeylerinin belirli yerlerinde bile mikro çukurlara yol açan çeşitli teğet şekil değişimleri meydana gelir. İşte buralarda oluşan daire, eliptik veya dikdörtgen temas yüzeyleri Hertz Teorisine göre açıklanmaktadır (Akkurt 1975). Yuvarlanmalı yataklar üzerine çeşitli çalışmalar uzun yıllardır yapılmaktadır. Hamrock ve Anderson (1983) yaptıkları detaylı çalışmalarda sabit bilyeli ve silindirik makaralı yuvarlanmalı yatakların tasarımını, kinematiğini, kullanılan malzemeleri, statik ve dinamik analizi ile sürtünme ve yağlama durumlarını incelemişlerdir. Pandiyarajan ve diğ. (2012) yaptıkları çalışmada uçakların gaz türbinlerinde ve nükleer reaktörlerde kullanılan büyük çaplı rulmanlı yatakların $(\mathrm{d}>400 \mathrm{~mm})$ çeşitli yükler altında kontak gerilmelerini nümerik ve analitik metotları kullanarak belirlemişlerdir. Sonuç olarak nümerik ve analitik metotların birbirleri ile uyumlu olduğu görülmüştür. Fernandes (1997) yaptığ çalışmada yataklar üzerinde etkili olan Hertz basınçlarının ve deformasyonlarının çalışma ömrü üzerine etkilerini incelemiştir. Çalışma ömrünün büyük ölçüde yük büyüklügüne ve temas yüzeylerinin birbirleri üzerindeki relatif hareketlerine bağlı olduğunu ortaya koymuştur. Amasorrain ve diğ. (2003) yaptıkları çalışmada dört noktadan temaslı tek sıralı yataklar için yeni bir hesap yöntemi geliştirip temas durumundaki gerilme dağılımını gösteren denklemleri ortaya koymuşlardır. Maksimum gerilme büyüklüğü ve yönü, temas alanı, eksenel ve radyal deplasmanlar, geliştirilen program vasıtasıyla hesaplanmıştır. Nelias ve diğ. (2005) yuvarlanmalı yataklardaki yorulma performansının değerlendirilmesi için yeni bir yöntem ortaya koymuşlardır. Yüzeyde hertz deformasyonları ile oluşan çukurcuklar modellenmiş ve çalışma nümerik ve deneysel olarak yürütülmüştür. Çeşitli yüksek alaşımlı çelikler çalışmada kullanılmıştır. Sonuçta çeşitli faktörlerin yorulma üzerine etkileri detaylıca incelenmiştir. Pipaniya ve Lodwal (2014) sabit bilyeli yuvarlanmalı yatakların bilye ile iç ve dış bileziklerinde meydana gelen temas gerilmelerini, elastik deformasyonları analitik ve sonlu elemanlar yöntemi kullanarak hesaplamışlardır. Antoine ve diğ. (2006) bilyeli rulmanlarda Hertz Teorisini kullanarak bilyelerin lokal rijitliklerini elde etmişlerdir. Hertz basınç ve deformasyonlarının hesabı için yeni bir metot teklif edilmiştir. Bu metot daha hassas hesapların yapılmasını sağlamaktadır.

$\mathrm{Bu}$ çalışmada bilyeli ve makaralı rulmanlar üzerinde etkili olan Hertz basınç ve deformasyonlarının çeşitli parametreler için değişimi incelenmiş ve karşılaştırmalı sonuçlar ortaya konmuştur. 


\section{MATERYAL VE METOT}

\subsection{Rulman Boyutları ve Malzeme özellikleri}

Çalışmada materyal olarak kullanılan yataklar sabit bilyeli ve silindirik makaralı olup farklı boyutlara ve malzeme çiftlerine sahiptir. Şekil 1' de rulmanların boyutları verilmiştir.

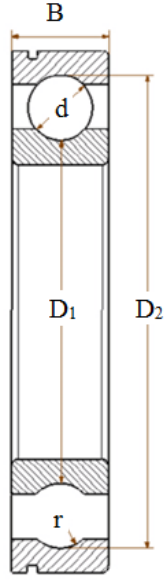

$a$.

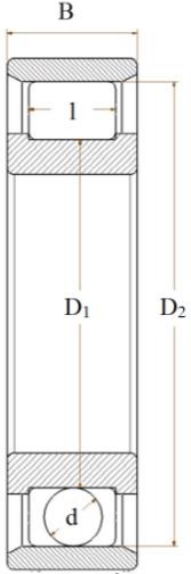

$b$.

Şekil 1:

Rulman Geometrisi

(a. Sabit bilyeli, b. Silindirik makaralı)

Burada $D_{1}$ iç bilezik yörünge çapını, $D_{2}$ dış bilezik yörünge çapını, $B$ rulman genişliği, $d$ bilye veya makara çapını, $\mathrm{r}$ yiv yarıçapını, 1 makara uzunluğunu ifade eder. Rulmanlarda bilye ve bilezik malzemesi olarak çelik ve seramik yaygın bir şekilde kullanılmaktadır.

Çalışmada kullanılan malzemelerin elastisite modülü ve poisson oranı Hertz deformasyonlarının tayininde önemli bir parametredir. Tablo 1 de malzemelerin bahsedilen mekanik özellikleri belirtilmiştir.

Tablo 1. Rulman Malzeme Özellikleri

\begin{tabular}{|l|c|l|}
\hline $\begin{array}{c}\text { Bilye-Bilezik } \\
\text { Malzemesi }\end{array}$ & $\begin{array}{c}\text { Elastisite } \\
\text { Modülü } \\
\left(\mathrm{N} / \mathrm{mm}^{2}\right)\end{array}$ & $\begin{array}{c}\text { Poisson } \\
\text { Oranı }\end{array}$ \\
\hline Çelik & 212000 & 0.30 \\
\hline Seramik & 314000 & 0.26 \\
\hline
\end{tabular}

\subsection{Hertz Basınç ve Deformasyon Dağılımı}

Sabit bilyeli rulmanlarda bilye ve bilezikler arasında eliptik bir temas yüzeyi oluşmaktadır. Nokta teması olarak da adlandırılan bu temasın şekli Şekil 2' de erilmiştir. 


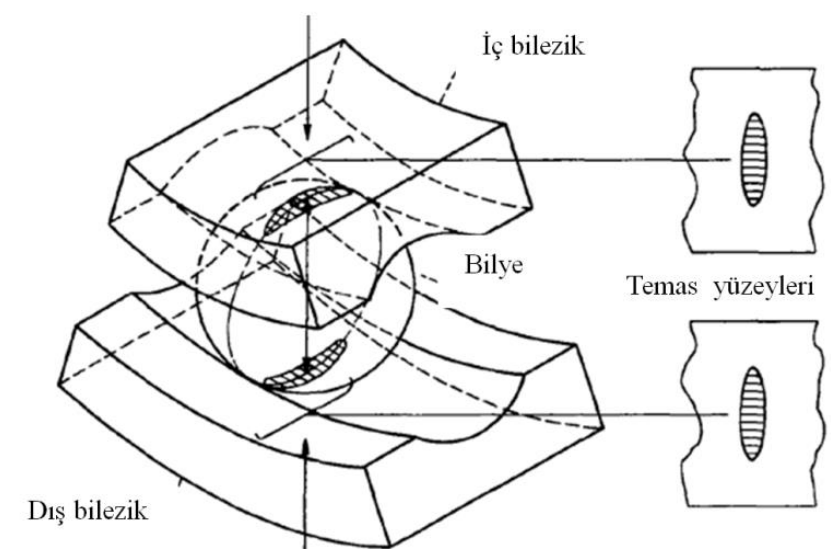

Şekil 2:

Sabit bilyeli rulmanlarda eliptik temas (Hamrock, 1983)

Böyle bir temasta oluşacak Hertz basınç dağılımı aşağıdaki gibi ifade edilir (Kayan ve Şuhubi, 1969).

$$
P(x, y)=p_{\text {maks }} \sqrt{1-\left(\frac{x}{b}\right)^{2}-\left(\frac{y}{a}\right)^{2}}
$$

Burada $P_{\text {maks }}$ oluşacak en büyük basınç değeridir ve şu şekilde yazılabilir.

$$
p_{\max }=\frac{3 F}{2 \pi a b}
$$

F bilye üzerindeki normal kuvveti, a eliptik yüzeyin uzun yarıçapı b ise kısa yarıçapını ifade etmektedir. Temas yüzeyinin ve oluşan basınç dağılımının görüntüsü Şekil 3' te verilmiştir.

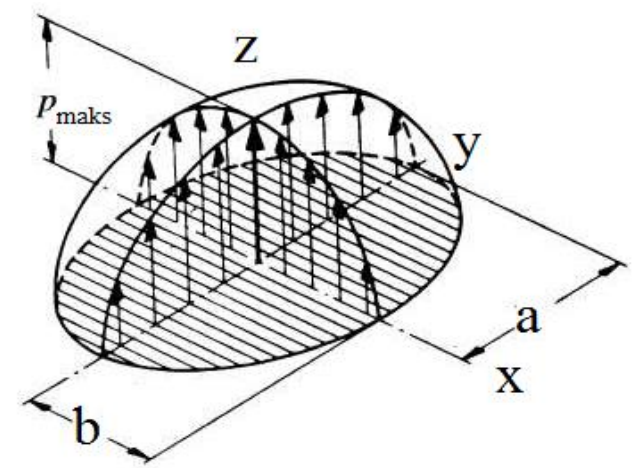

Şekil 3:

Eliptik temas yüzeyindeki basınç dağılımı (Brüser, 1972)

Şekil 4' te böyle bir temasta oluşan Hertz basınç ve deformasyon alanları görülmektedir. 


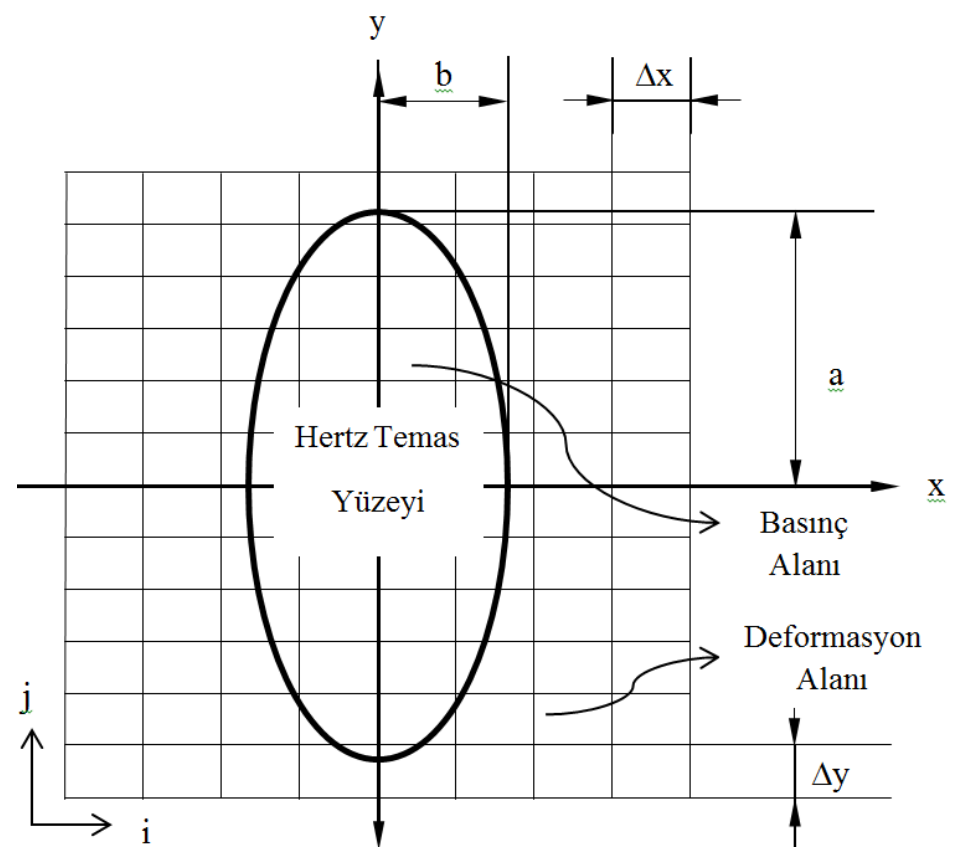

Şekil 4:

Sabit bilyeli rulmanlarda Hertz basınç ve deformasyon alanı

Eliptik yüzeyin yarıçap değerleri ise aşağıdaki ifadelerle bulunmaktadır (İleri, 1973).

$$
\begin{gathered}
a=1,4 . \xi \cdot \sqrt[3]{\frac{F \cdot\left(k_{1}+k_{2}\right)}{2 A B}} \\
b=1,4 . \vartheta \cdot \sqrt[3]{\frac{F \cdot\left(k_{1}+k_{2}\right)}{2 A B}}
\end{gathered}
$$

Burada $\mathrm{k}_{1}$ ve $\mathrm{k}_{2}$ poisson oranı ve elastisite modülüne bağlı bir ifadedir. AB ise temas eden bilyebilezik çiftinin $x z$ ve yz düzlemlerindeki eğriliklerinin toplamıdır. $k_{1}, k_{2}$ ve $A B$ değerini veren ifadeler aşağıdaki gibidir. Bu denklemlerde $v$ poisson oranını, $\mathrm{E}$ ise elastisite modülünü ifade etmektedir.

$$
\begin{gathered}
k_{1,2}=\frac{1-v_{1,2}^{2}}{E_{1,2}} \\
A B=\left(\frac{1}{R_{1}}+\frac{1}{R_{2}}+\frac{1}{R_{3}}+\frac{1}{R_{4}}\right)
\end{gathered}
$$

(6) ifadesinde $R_{1}$ ve $R_{3}$ bilyenin veya makaranın $x z$ ve yz düzlemlerindeki yarıçaplarını, $R_{2}$ bileziğin yörünge yarıçapını ve $\mathrm{R}_{4}$ ise bileziğin yiv yarıçapını ifade eder. Bilyeli yataklarda $\mathrm{R}_{1}=\mathrm{R}_{3}$ olacağ 1 , makaralı yataklarda ise $\mathrm{R}_{1}=\mathrm{R}_{4}=\infty$ olacağı aşikârdır. 
Şekil 5' te düzlemlerdeki eğrilik yarıçapları görülmektedir.
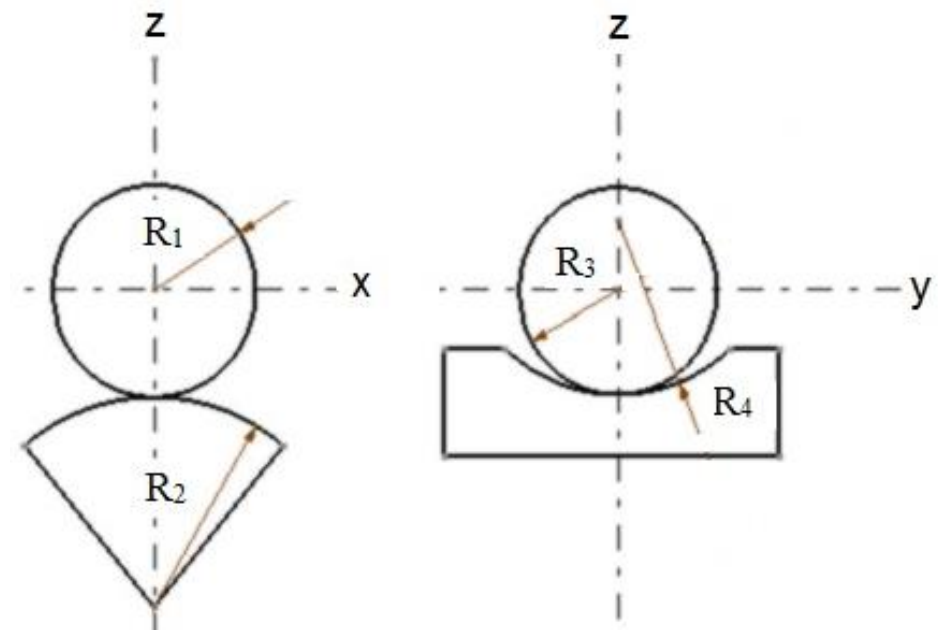

Şekil 5:

$x z$ ve $y z$ düzlemlerindeki eğrilik yarıçapları

a, b denklemlerinde kullanılan $\xi, \vartheta$ değerleri ise $\cos \varphi$ olarak tanımlanan yardımcı bir değere bağlı olarak bulunabilir.

$$
\cos \varphi=\left(\frac{\frac{1}{R_{2}}-\frac{1}{R_{4}}}{\frac{1}{R_{1}}+\frac{1}{R_{2}}+\frac{1}{R_{3}}+\frac{1}{R_{4}}}\right)
$$

Bu değer, olarak ifade edilir. $\varphi$ açısına göre $\xi$ ve $\vartheta$ değerleri Tablo 2' deki gibidir (İleri, 1973).

Tablo 2. $\operatorname{Cos}(\varphi x)$ değerine göre $\xi$ ve $\vartheta$ değerleri

\begin{tabular}{|l|l|l|l|l|l|l|}
\hline $\operatorname{Cos}(\varphi)$ & 0 & 0,4 & 0,5 & 0,6 & 0,7 & 0,750 \\
\hline$\xi$ & 1 & 1,35 & 1,48 & 1,66 & 1,91 & 2,07 \\
\hline$\vartheta$ & 1 & 0,769 & 0,718 & 0,664 & 0,608 & 0,577 \\
\hline $\operatorname{Cos}(\varphi)$ & 0,80 & 0,85 & 0,90 & 0,925 & 0,950 & 0,975 \\
\hline$\xi$ & 2,295 & 2,57 & 3,06 & 3,5 & 4,14 & 5,22 \\
\hline$\vartheta$ & 0,545 & 0,509 & 0,462 & 0,432 & 0,395 & 0,352 \\
\hline
\end{tabular}

Silindirik makaralı rulmanlarda ise makara ile bileziğin teması sonucu dikdörtgen șekle sahip bir yüzey oluşur. Makaralı rulmanlarda temas yüzeyi ve oluşan basınç dağılımı Şekil 6' te verilmiştir. 


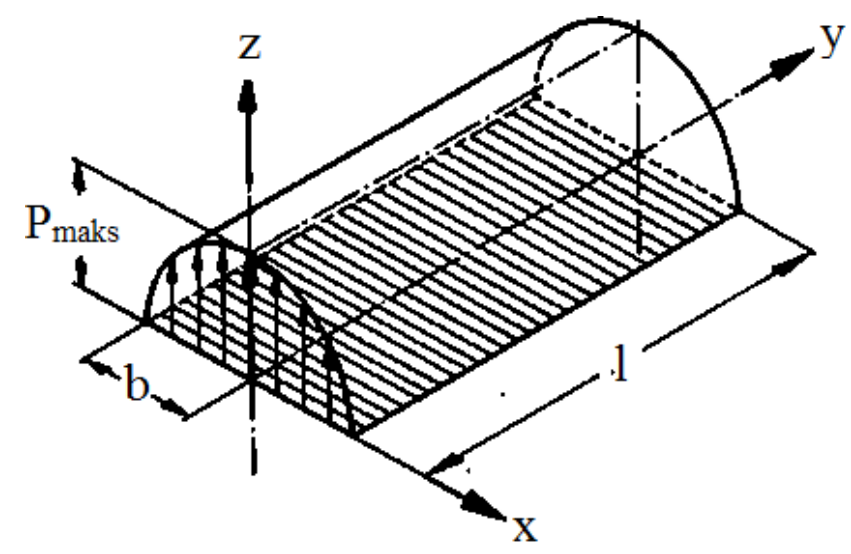

Şekil 6:

Dikdörtgen temas yüzeyindeki basınç dağılımı (Brüser, 1972)

Böyle bir temasta oluşacak Hertz basınç dağılımı şu şekilde ifade edilir.

$$
P(x)=p_{m a k s} \cdot \sqrt{1-\left(\frac{x}{b}\right)^{2}}
$$

Burada $P_{\text {maks }}$ oluşacak en büyük basınç değeridir ve şu şekilde ifade edilir (Brüser, 1972).

$$
p_{\max }=\frac{2 F}{\pi b l}
$$

1 makara uzunluğu olup, $b$ aşağıdaki gibi ifade edilir.

$$
b=\sqrt{\frac{4 F \cdot\left(k_{1}+k_{2}\right)}{A B \cdot \pi \cdot l}}
$$

Burada yine temas yüzeyindeki her bir noktada Hertz basınçlarını ve daha sonra deformasyonları hesaplamak için temas yüzeyi $\Delta \mathrm{x}$ ve $\Delta \mathrm{y}$ boyutlarına sahip küçük alanlara ayrılmaktadır. Bu durum Şekil 7' de belirtilmiştir.

Sabit bilyeli ve silindirik makaralı rulmanlarda elastik deformasyonlar belli bir değeri aştığında plastik deformasyonlara sebep olabilir. Bu sebeple kontrol edilmeleri gerekmektedir. Şekil 8' de oluşan Hertz basınç ve deformasyon arasındaki ilişki gösterilmiştir.Şekil 8' de $r=\sqrt{\left(x-x_{1}\right)^{2}+\left(y-y_{1}\right)^{2}}$ dir.

Hertz basınçlarının temas yüzeyi boyunca sebep olduğu elastik deformasyonlar şu şekilde ifade edilebilir (Brüser, 1972).

$$
w(x, y)=\frac{\left(1-v^{2}\right)}{\pi E} \iint \frac{P\left(x_{1}, y_{1}\right) \Delta x \Delta y}{r}
$$

Bu denklemde $\mathrm{w}(\mathrm{x}, \mathrm{y})$ deformasyon miktarını, $\mathrm{x}$ ve $\mathrm{y}$ deformasyonu hesaplanacak olan noktanın koordinatlarını, $\mathrm{P}\left(\mathrm{x}_{1}, \mathrm{y}_{1}\right)$ deformasyona neden olan basınç değerini, $\mathrm{x}_{1}$ ve $\mathrm{y}_{1}$ ise bu deformasyona 
neden olan basıncın oluştuğu koordinatı göstermektedir. $\Delta \mathrm{x}$ ve $\Delta \mathrm{y}$ ise ağ yapısı içinde $\mathrm{x}$ ve $\mathrm{y}$ doğrultularındaki birim ağ elemanının boyutlarıdır. Bu durumda bir noktada meydana gelen deformasyonu hesaplayabilmek için; temas yüzeyinde oluşan tüm basınçların o noktada oluşturdukları deformasyonları toplamak gerekmektedir. Yani denklem şu hale gelmektedir (Brüser, 1972).

$$
w(x, y)=\frac{\left(1-v^{2}\right)}{\pi E} \sum_{x=x \min }^{x=x \max } \sum_{y=y \min }^{y=y \max } \frac{P\left(x_{1}, y_{1}\right) \Delta x \Delta y}{r}
$$

Ancak $\mathrm{x}_{1}=\mathrm{x}$ ve $\mathrm{y}_{1}=\mathrm{y}$ noktasında yani, yükün etki ettiği nokta ile meydana gelen deformasyonun hesaplanacağı nokta aynı olduğunda, sonuç sonsuz çıkmaktadır. Bu nedenle bu noktadaki deformasyon integral işlemi alınarak bulunmak zorundadır. $\mathrm{Bu}$ integral işlemi ağ yapısının birim elemanına göre şöyle alınabilir (Brüser, 1972).

$$
w^{\prime}=\frac{\left(1-v^{2}\right)}{\pi E} \cdot P\left(x_{1}, y_{1}\right) \cdot 2 \Delta x \cdot\left[\sqrt{1+\left(\frac{\Delta y}{\Delta x}\right)^{2}} \ln \left(\frac{\sqrt{1+\left(\frac{\Delta y}{\Delta x}\right)^{2}}}{\sqrt{1+\left(\frac{\Delta y}{\Delta x}\right)^{2}}-1}\right)+\ln \left(\sqrt{1+\left(\frac{\Delta y}{\Delta x}\right)^{2}}-1\right)\right]
$$

Elastik deformasyon w' ile w ifadelerinin toplamından bulunmaktadır. Denklem (13) MATLAB ortamında programlanarak farklı parametreler için program çalıştırılmıştır. Şekil 9' da program arayüzü görülmektedir.

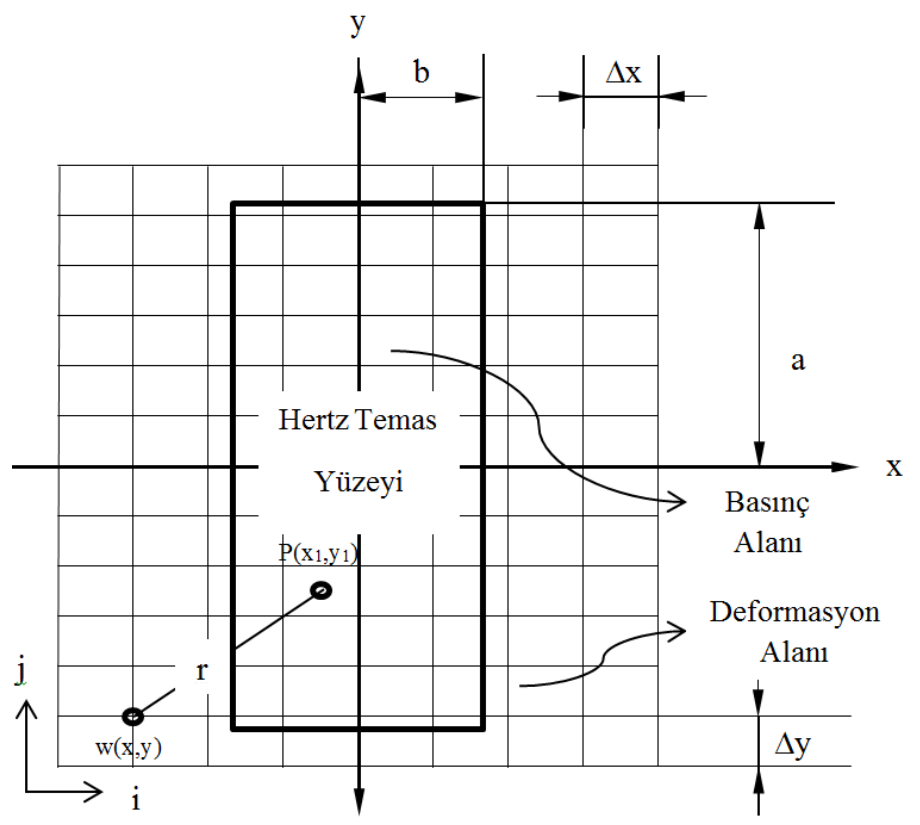

Şekil 7:

Silindirik makaralı rulmanlarda Hertz basınç ve deformasyon alanı 


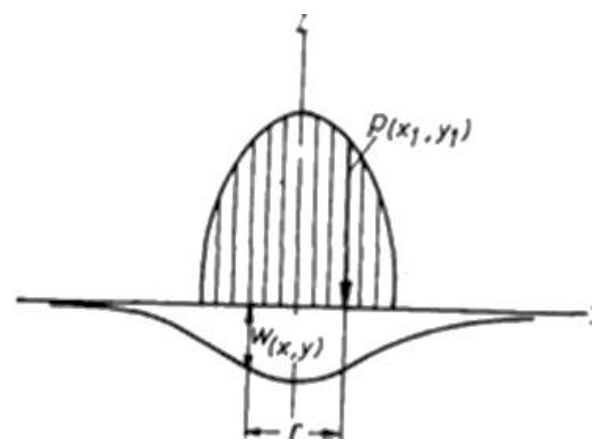

Şekil 8:

Hertz basinç deformasyon ilişkisi (Brüser, 1972)

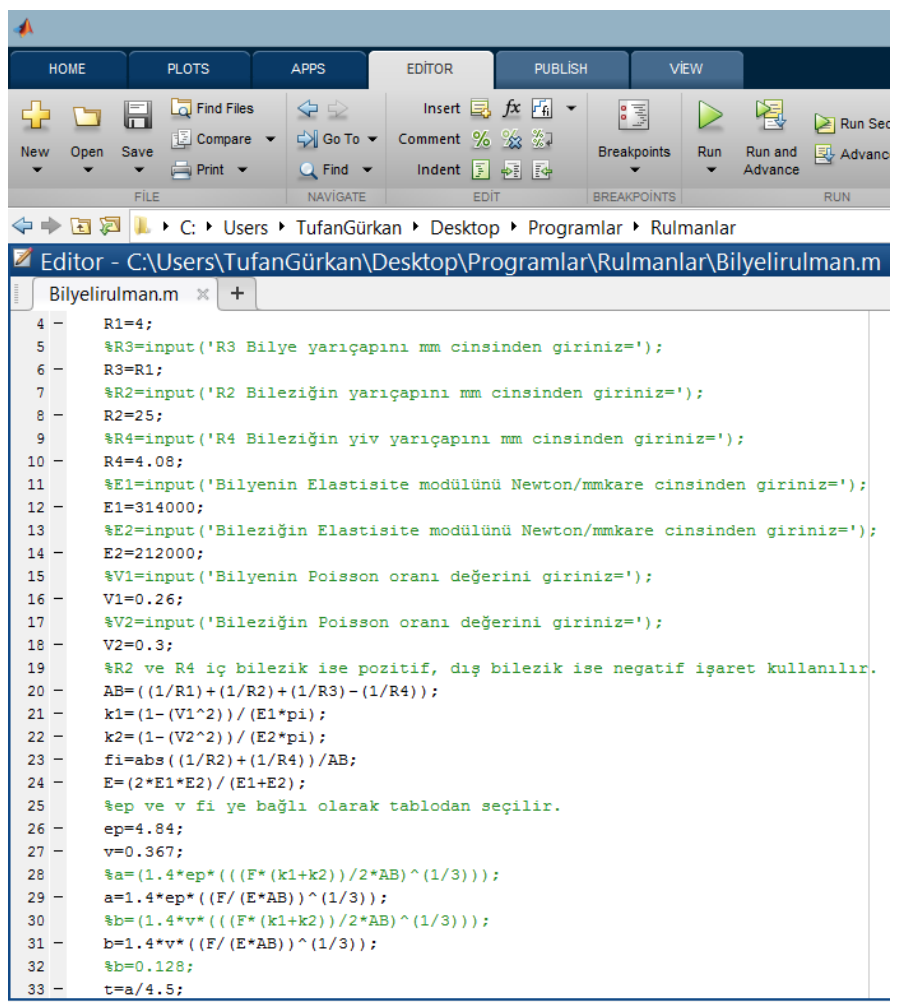

\section{Şekil 9:}

MATLAB program ara yüzü

\section{BULGULAR}

$\mathrm{Bu}$ bölümde geliştirilen bilgisayar programı vasıtasıyla çeşitli yük değerleri için farklı malzeme çiftleri, yiv yarıçapları, yörünge yarıçapları, yörünge uygunluk oranlarına sahip bilyeli ve silindirik makaralı yataklarda bilye ve makarada meydana gelen Hertz basınçları ve elastik deformasyonlar elde edilmiş ve sonuçlar birbirleriyle mukayese edilmiştir. Elde edilen sonuçlara göre daha kritik olması bakımından sadece iç bilezikler incelenmiştir. Burada önemli bir büyüklük olarak yörünge uygunluk oranı, yiv yarıçapının (r) bilye çapına (d) oranıdır. Bu oran yaygın olarak 0.51 ile 0.54 arasında değişmektedir (Hamrock, 1983). 
Güllü E., Yılmaz T.G.: Rulmanlı Yataklarda Hertz Basınçlarının ve Yuvarlanmayla Oluşan D. Analizi

Analiz I de kullanılan boyut, malzeme ve yük değerleri Tablo 3’ de verilmiştir.

Tablo 3. Analiz I değerleri

\begin{tabular}{|c|c|c|c|}
\hline \multirow{2}{*}{ Bilye-Bilezik Malzemesi } & \multicolumn{3}{|c|}{$\begin{array}{c}\text { Çelik-Çelik } \\
\text { Seramik-Çelik } \\
\text { Seramik-Şramik }\end{array}$} \\
\hline d (Bilye çapı-mm) & 8 & 9 & 10 \\
\hline $\mathrm{D}_{1}$ (İç bilezik yörünge çapı-mm) & 50 & 50 & 50 \\
\hline r/d (Yörünge uygunluk oranı) & 0,51 & 0,51 & 0,51 \\
& 0,525 & 0,525 & 0,525 \\
& 0,54 & 0,54 & 0,54 \\
\hline F & 1000 & 1000 & 1000 \\
& 2000 & 2000 & 2000 \\
& 3000 & 3000 & 3000 \\
& 4000 & 4000 & 4000 \\
& 5000 & 5000 & 5000 \\
\hline
\end{tabular}

Analiz II de kullanılan boyut, malzeme ve yük değerleri Tablo 4' de verilmiştir.

Tablo 4. Analiz II değerleri

\begin{tabular}{|c|c|c|c|}
\hline \multirow{2}{*}{ Makara-Bilezik Malzemesi } & \multicolumn{3}{|c|}{$\begin{array}{c}\text { Çelik-Çelik } \\
\text { Seramik- Çelik } \\
\text { Seramik-Seramik }\end{array}$} \\
\hline d (Makara çap1 -mm) & 8 & 9 & 10 \\
\hline 1 (Makara uzunluğu -mm) & 30 & 30 & 30 \\
\hline D $_{1}$ (İç bilezik yörünge çap1 -mm) & 50 & 50 & 50 \\
\hline & 1000 & 1000 & 1000 \\
F & 2000 & 2000 & 2000 \\
(Normal Kuvvet-N) & 3000 & 3000 & 3000 \\
& 4000 & 4000 & 4000 \\
& 5000 & 5000 & 5000 \\
\hline
\end{tabular}

Bu kısımda Analiz I ve II' deki çeşitli durumlar için Hertz basınç ve deformasyon dağılımları ile bilye ve makara çapının, yörünge oranının ve malzeme çiftinin değişiminin etkileri incelenmiştir.

Bunlardan malzeme değişiminin bilyeli rulmanlarda yuvarlanma elemanları üzerindeki etkisi Tablo 5 de belirtilmiştir. 
Tablo 5. $\mathrm{F}=1000 \mathrm{~N}$ d=8 $\mathrm{mm}$ bilye çapı $\mathrm{r} / \mathrm{d}=0.51$ için oluşan maksimum Hertz basıncı ve maksimum deformasyonlar

\begin{tabular}{|c|c|c|c|}
\hline $\begin{array}{c}\text { Bilye-Bilezik } \\
\text { Malzeme Çifti }\end{array}$ & $\begin{array}{c}\text { Hertz Basınc1 } \\
\left(\mathrm{N} / \mathrm{mm}^{2}\right)\end{array}$ & $\begin{array}{c}\mathrm{W}_{1} \\
\text { Bilye Deformasyonu (mm) }\end{array}$ & $\begin{array}{c}\mathrm{W}_{2} \\
\text { Bilezik } \\
\text { Deformasyonu (mm) }\end{array}$ \\
\hline Çelik-Çelik & 2160,3 & 0,0081 & 0,0081 \\
\hline Seramik-Çelik & 2431,3 & 0,006 & 0,0086 \\
\hline $\begin{array}{c}\text { Seramik- } \\
\text { Seramik }\end{array}$ & 2807 & 0,0064 & 0,0064 \\
\hline
\end{tabular}

Yine aynı şartlar için Hertz basıncı ile bilyede oluşan deformasyon dağılımı örnek olarak Şekil 10 ' da verilmiştir.
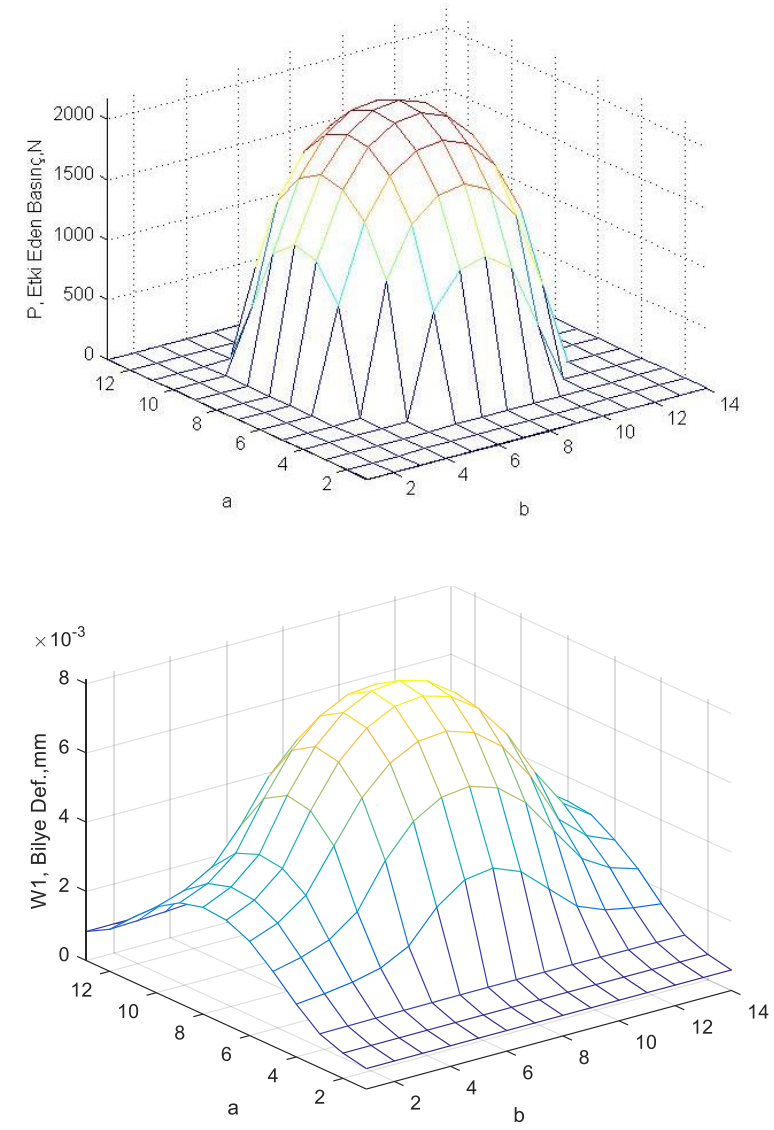

\section{Şekil 10:}

$F=1000 \mathrm{Nd}=8 \mathrm{~mm}$ bilye çapı $\mathrm{r} / \mathrm{d}=0.51$ çelik-çelik malzeme çifti için Hertz basınç ve deformasyonlarının dağılımı

Şekil 11' de Analiz I' deki şartlarda yörünge uygunluk oranının Hertz basıncı ve deformasyonlar üzerine etkisi görülmektedir. 
Güllü E., Yılmaz T.G.: Rulmanlı Yataklarda Hertz Basınçlarının ve Yuvarlanmayla Oluşan D. Analizi

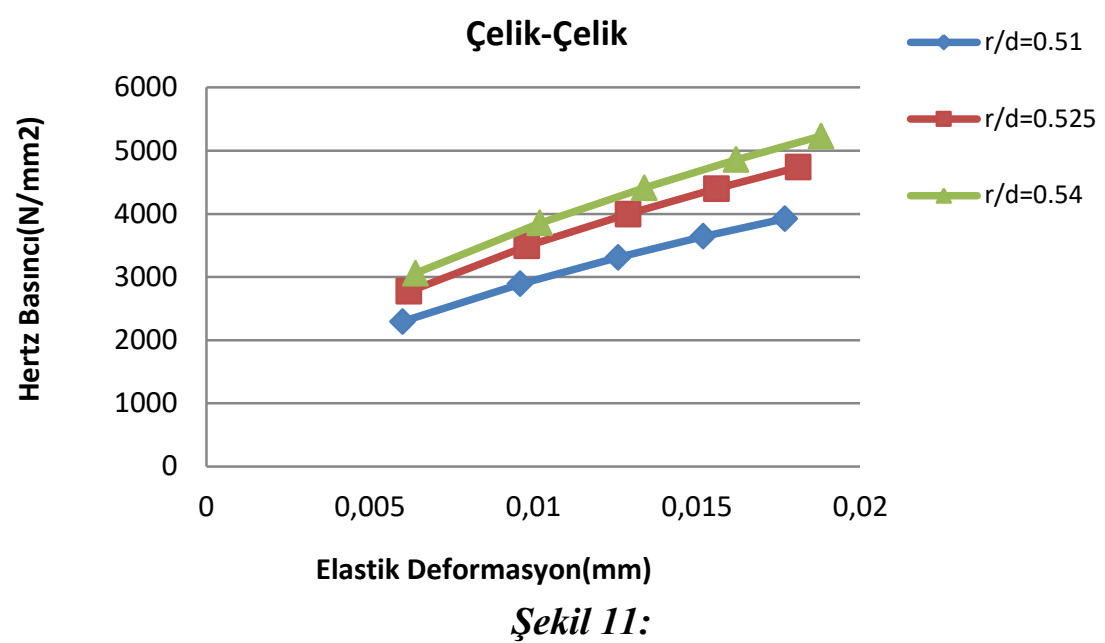

Yörünge uygunluk oranının bilye ve iç bilezikte oluşan Hertz basınç ve deformasyonlarına etkisi $(d=8 \mathrm{~mm}, F=1000-5000 \mathrm{~N})$

Şekil 12' de aynı şartlarda Seramik-Çelik malzeme çiftinde oluşan Hertz basınç ve deformasyonları gösterilmiştir.

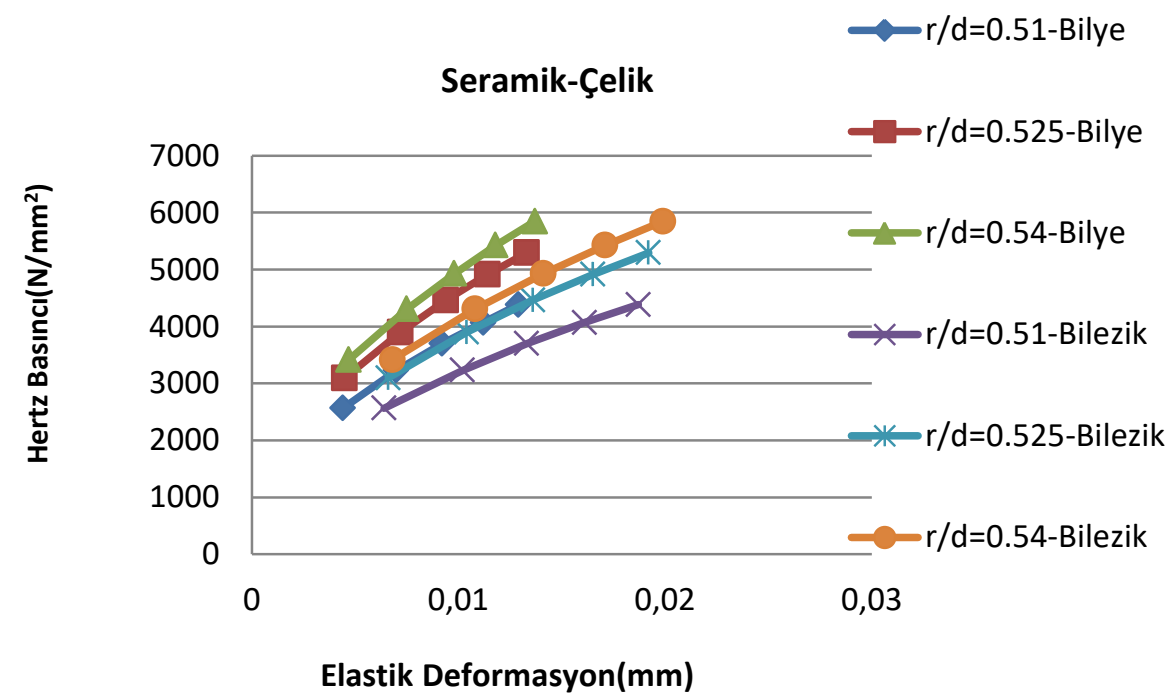

Şekil 12:

Yörünge uygunluk oranının Hertz basınç ve deformasyonlarına etkisi $(d=8 \mathrm{~mm}, F=1000-5000 \mathrm{~N})$

Şekil 13' de ise yine Analiz I deki durumlardan $\mathrm{r} / \mathrm{d}=0.51$ için çelik-çelik malzeme çiftinde, bilye çapının değişiminin oluşan Hertz basıncı ve deformasyonlar üzerine etkisi gösterilmiştir. 

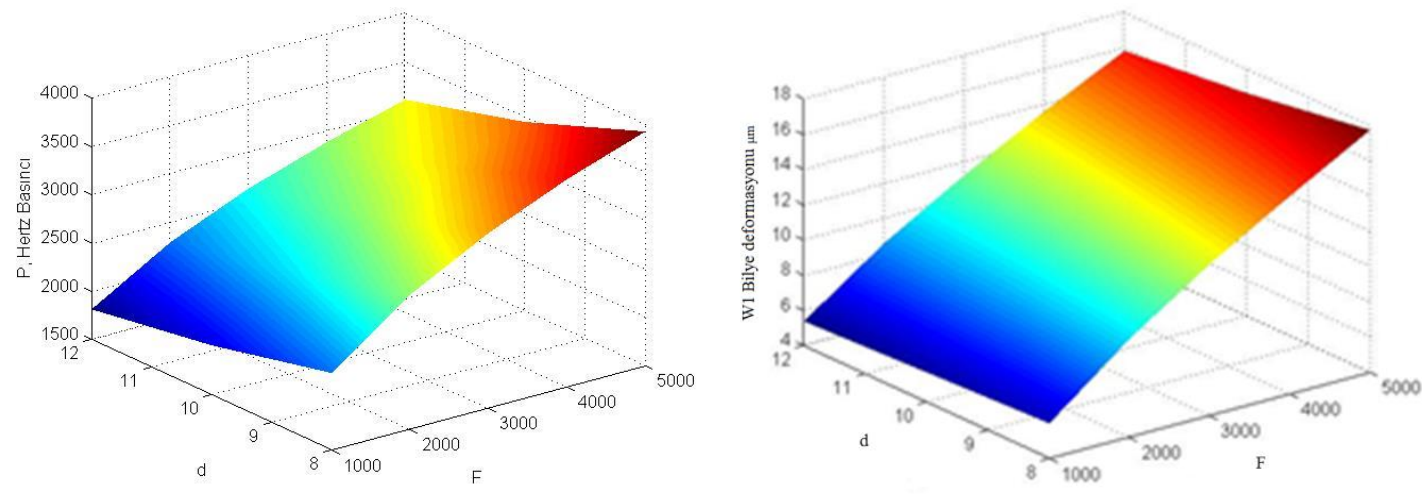

\section{Şekil 13:}

$r / d=0.51$ için çelik-çelik malzeme çiftinde bilye çapının oluşan Hertz basınç ve deformasyonları üzerine etkisi

Silindirik makaralı rulman için $\mathrm{d}=10 \mathrm{~mm}$ makara çapı ve Seramik-Seramik malzeme çiftinde $\mathrm{F}=5000 \mathrm{~N}$ da oluşan Hertz basıncı ile bilyedeki deformasyon dağılımı örnek olarak Şekil 14' de verilmiştir.
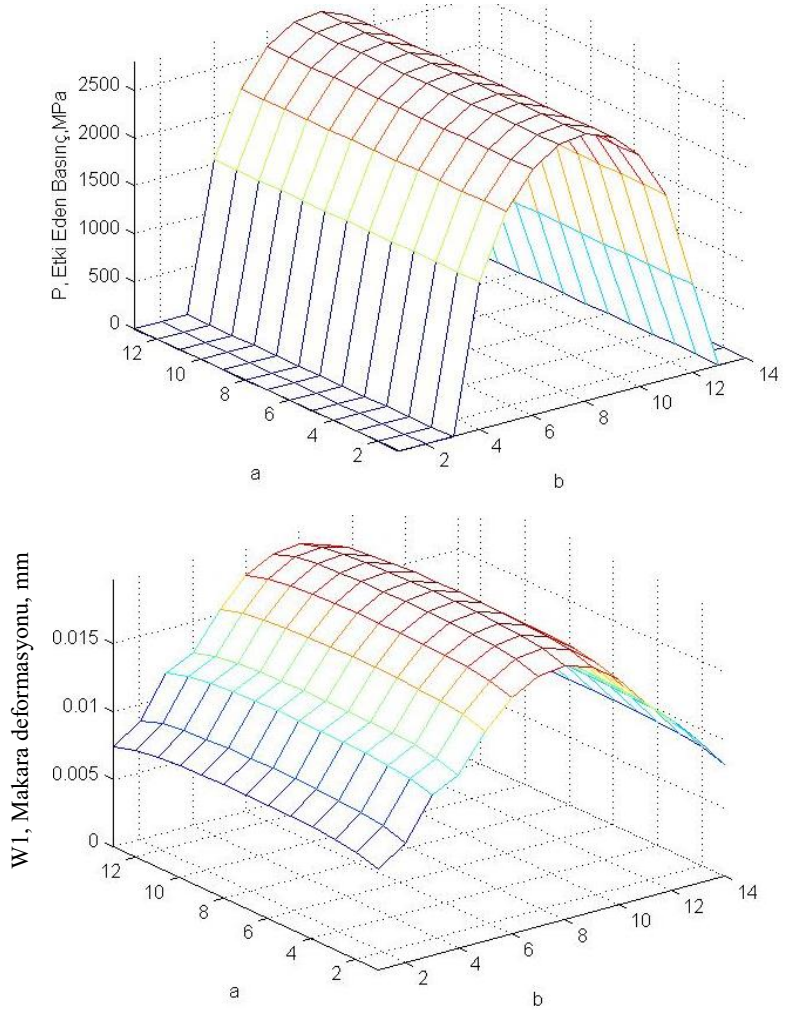

Şekil 14:

$F=5000 \mathrm{Nd}=10 \mathrm{~mm}$ makara çapl, seramik-seramik malzeme için Hertz basınç ve deformasyonlarının dă̆ılımı

Ayrıca aynı durumlar için Tablo 6 da farklı malzeme çiftlerinde oluşan maksimum Hertz basıncı ve deformasyonları belirtilmiştir. 
Tablo 6. $\mathrm{F}=5000 \mathrm{~N}$ d=10 mm makara çapı için oluşan maksimum Hertz basıncı ve maksimum deformasyonlar

\begin{tabular}{|l|l|l|l|}
\hline $\begin{array}{l}\text { Makara-Bilezik } \\
\text { Malzeme Çifti }\end{array}$ & $\begin{array}{l}\text { Hertz } \\
\text { Basınc1 } \\
\left(\mathrm{N} / \mathrm{mm}^{2}\right)\end{array}$ & $\begin{array}{l}\mathrm{W}_{1} \\
\text { Makara Deformasyonu } \\
(\mathrm{mm})\end{array}$ & $\begin{array}{l}\mathrm{W}_{2} \\
\text { Bilezik } \\
\text { Deformasyonu(mm) }\end{array}$ \\
\hline Çelik-Çelik & 5135,5 & 0,0698 & 0,0698 \\
\hline Seramik-Çelik & 5583 & 0,051 & 0,0738 \\
\hline Seramik-Seramik & 6174 & 0,0549 & 0,0549 \\
\hline
\end{tabular}

Bir karşılaştırma yapmak için aynı ağırlığa sahip bir makaralı rulman ile sabit bilyeli rulmanda oluşan Hertz basınçları Tablo 7' de sunulmuştur.

Tablo 7. Aynı ağırlığa sahip silindirik makaralı ve sabit bilyeli rulmanlarda oluşan hertz basınçları

\begin{tabular}{|c|c|c|}
\hline & & \\
& Silindirik Makaralı Rulman & Sabit Bilyeli Rulman \\
\hline Malzeme çifti & Çelik-Çelik & Çelik-Çelik \\
\hline Kuvvet $(\mathrm{N})$ & 1000 & 1000 \\
\hline Hertz basıncı $\left(\mathrm{N} / \mathrm{mm}^{2}\right)$ & 1424,4 & 2177,4 \\
\hline
\end{tabular}

Burada $\mathrm{d}=8 \mathrm{~mm}$ alınmış olup bilye hacmi ile makara hacmi birbiri ile eşitlenerek makaranın 1 uzunluğu yaklaşık 5,3 mm olarak bulunup hesap yapılmıştır

Şekil 15' de Analiz II deki durumlar için silindirik makaralı rulmanlarda $\mathrm{d}=8 \mathrm{~mm}$ makara çapında malzeme değişiminin Hertz basınç ve deformasyonları üzerine etkisi gösterilmiştir.

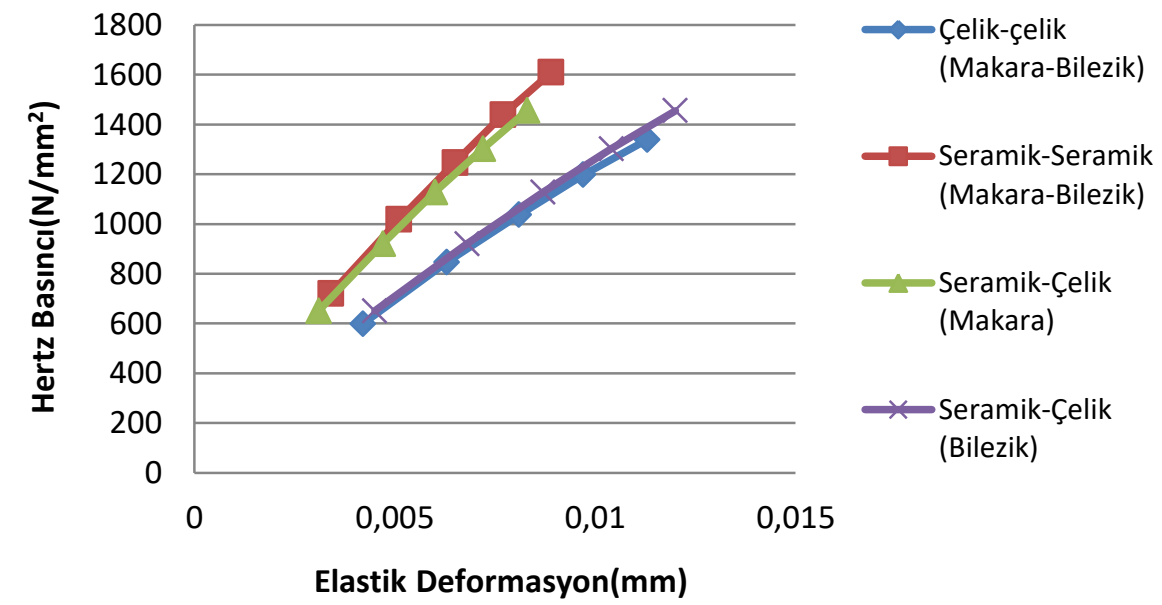

Şekil 15:

$d=8 \mathrm{~mm}$ makara çapı için malzeme çifti değişiminin makara ve iç bilezikteki Hertz Basınç ve deformasyonlart üzerine etkisi $(F=1000-5000 \mathrm{~N})$ 
Şekil 16' da aynı şartlarda değişen makara çapının çelik-çelik malzeme çifti için Hertz basınçları üzerine etkisi gösterilmiştir.

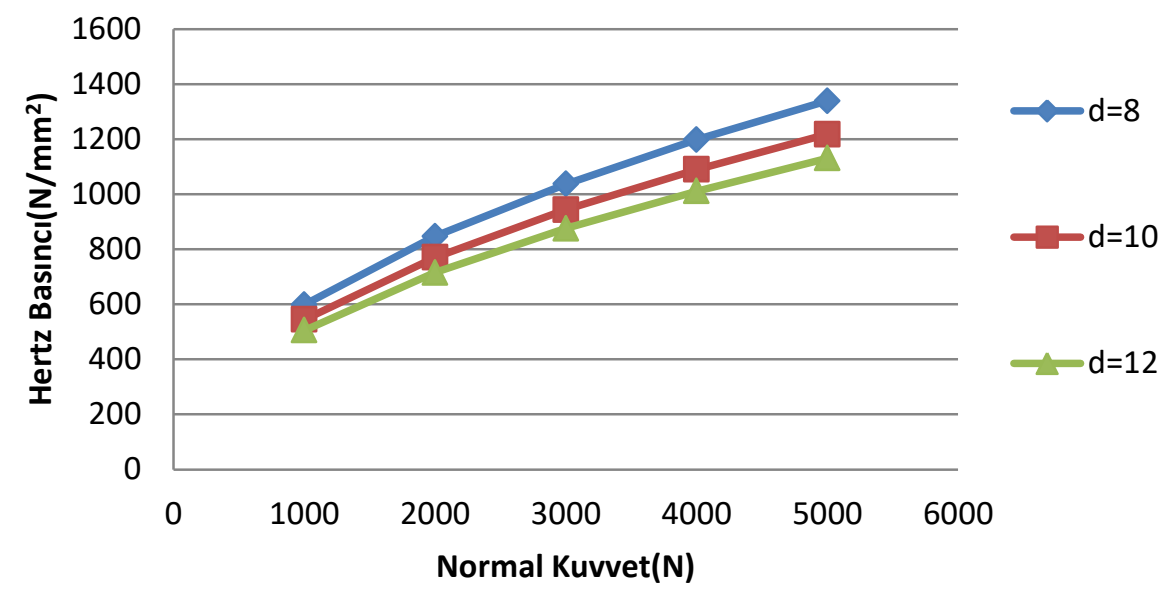

Şekil 16:

Makara çapının Çelik-Çelik çifti için Hertz Basınçları üzerine etkisi

\section{SONUÇLAR}

$\mathrm{Bu}$ çalışmada rulmanlarda etkili olan Hertz basınçlarına ve deformasyonlarına çeşitli faktörlerin etkisi incelenmiştir. İnceleme neticesinde şu önemli sonuçlara ulaşılmıştır;

- Farklı malzemelerden yapılmış bilezik ve yuvarlanma elemanı kullanıldı̆̆ında, yuvarlanma elemanının malzemesinin elastisite modülünün bilezik elemanının malzemesinin elastisite modülüne göre daha büyük bir değerde seçildiğinde deformasyon değerlerinin düştüğü görülmektedir. Örneğin, malzeme olarak çelik ve seramik kullanılacaksa, yuvarlanma elemanını seramikten, bileziği ise çelik malzemeden seçmek daha uygundur.

- Kullanılan malzemeye göre inceleme yapıldığında seramikten yapılmış bilye ve makaraların, çelikten yapılmış olanlara göre daha az deformasyona uğradıkları görülmektedir.

- Önemli bir parametre olan yörünge uygunluk oranının artması ile Hertz basınç ve deformasyonlarının arttığı gözlenmiştir.

- -Bilye ve makara çapının artması ile oluşan Hertz basınç ve deformasyonlarının azaldığı görülmüştür.

- -Sabit bilyeli rulman ile aynı ağırlı̆ga ve malzemeye sahip silindirik makaralı rulmanda oluşan Hertz basıncı daha küçüktür.

- Hertz basıncına maruz malzemelerde plastik deformasyon için belli bir limit bulunmaktadır. $\mathrm{Bu}$ değer pmaks $\times \sqrt[3]{\mathrm{d}}$ dir. Burada pmaks temas yüzeyinde oluşan maksimum Hertz basıncı ve d ise bilye çapıdır. Limit değerler ile bu değer mukayese edilerek çalışma güvenliği kontrol edilebilir.

\section{KAYNAKLAR}

1. Akkurt M. (1975) Makine Elemanları, İstanbul Teknik Üniversitesi Matbaası, İstanbul. 
2. Amasorrain J.I., Sagartsazu X. ve Damian J. (2003) Load distribution in a four contact-point slewing bearing, Mechanism and Machine Theory, 38(6), 479-496, doi:10.1016/S0094$114 \mathrm{X}(03) 00003-\mathrm{X}$

3. Antoine J-F., Visa C., Sauvey C. Ve Abba G. (2006) Approximate Analytical Model For Hertzian Elliptical Contact Problems, Journal of Tribology, 128(3). doi:10.1115/1.2197850

4. Brüser P. (1972). Untersuchungen über die elastohydrodynamische Schmierfilmdicke bei elliptischen Hertzschen Kontaktflächen, Doktora Tezi, Carolo-Wilhelmina Teknik Üniversitesi.

5. Fernandes P.J.L. (1997) Contact Fatigue in Rolling-Element Bearings, Engineering Failure Analysis, 4(2), 155-160. doi:10.1016/S1350-6307(97)00007-1

6. Hamrock J. ve Anderson W. (1983) Rolling-Element Bearings, NASA Reference Publication, Lewis Research Center, USA.

7. İleri, H. (1973) Makine Elemanları Hesabı, İstanbul Teknik Üniversitesi Matbaası, İstanbul.

8. Kayan İ. ve Şuhubi E. (1969) Elastisite Teorisi, Arı Kitapevi Matbaası, İstanbul.

9. Nelias D., Jacq C., Lormand G., Dudrange G. ve Vincent A. (2005) New Methodology to Evaluate the Rolling Contact Fatigue Performance of Bearing Steels With Surface Dents: Application to 32CrMoV13 Nitrided and M50 Steels, Journal of Tribology, 127(3), 611622. doi:10.1115/1.1924462

10. Pandiyarajan R., Starvin M.S. ve Ganesh K.C. (2012) Contact Stress Distribution of Large Diameter Ball Bearing Using Hertzian Elliptical Contact Theory, International Conference on Modelling Optimization and Computing, Procedia Engineering, 38, 264-269. doi:10.1016/j.proeng.2012.06.034

11. Pipaniya S. ve Lodwal A. (2014) Contact Stress Analysis of Deep Groove Ball Bearing 6210 Using Hertzian Contact Theory, International Journal of Innovative Research in Engineering \& Science, 7(3), 8-16. 